\title{
Flow-seaweed interactions of Saccharina latissima at a blade scale: turbulence, drag force, and blade dynamics
}

\author{
Davide Vettori $^{1,2}$ D $\cdot$ Vladimir Nikora $^{1}$
}

Received: 16 April 2018 / Accepted: 19 July 2019 / Published online: 27 July 2019

(c) The Author(s) 2019

\begin{abstract}
Physical interactions between seaweed blades of Saccharina latissima and unidirectional turbulent flow were examined in an open-channel flume, focussing on flow velocities, drag force acting on a blade, and blade reconfiguration. The data reveal that seaweed blades adjust to high-energy flow conditions relatively quickly, efficiently reducing flow-induced drag via compaction, a mechanism of blade reconfiguration. The drag coefficient of blades of S. latissima varied between 0.02 and 0.07 over a range of mean flow velocities from 0.1 to $0.55 \mathrm{~m} / \mathrm{s}$. Both flow action and blade biomechanical characteristics influenced the blade dynamics, with the flow role being predominant in highly energetic conditions. The interaction mechanisms and their strength were found to be scale-dependent, with the combined effect of reduced mean flow velocity and enhanced turbulence in blade wakes. The thickness of the diffusive boundary layer, an important factor in nutrient uptake from the surrounding water, was estimated to be in the range from 0.010 to $0.067 \mathrm{~mm}$. Mechanisms of blade adjustment to the flow and scale-dependent dynamic interactions between blades and turbulent eddies have direct implications for seaweed growth, acclimation, and survival. The estimates of the drag coefficient and the thickness of the diffusive boundary layer will be useful for the development of bio-physical models, environmental assessments, and design of seaweed farms.
\end{abstract}

Keywords Seaweeds $\cdot$ Flow-vegetation interaction $\cdot$ Turbulence $\cdot$ Drag force $\cdot$ Reconfiguration $\cdot$ Diffusive boundary layer

\section{Introduction}

The uptake rate of nutrients by seaweeds depends on physical and/or biochemical factors, as discussed by Hurd (2000) who provides a comprehensive review of seaweed physiology and production. At low flow velocities, photon flux density and mass transfer to the seaweed surface through the diffusive boundary layer (DBL) are the main limiting factors for seaweed growth rate (e.g. Wheeler 1980; Hurd 2000). As flow velocity increases, the DBL becomes thinner and thus mass transfer across it is enhanced, making nutrient uptake to be limited mainly by biochemical factors such as enzymes (Koch 1994). To overcome the disadvantage of low flow velocity, seaweeds growing in sheltered environments

Davide Vettori

d.vettori@lboro.ac.uk

1 School of Engineering, University of Aberdeen, Aberdeen, Scotland AB24 3UE, UK

2 Present Address: Department of Geography and Environment, Loughborough University, Loughborough, Leicestershire LE11 3TU, UK are known to develop ruffles on their blades to maximise blade movements to limit self-shading and thus enhance photosynthesis (e.g. Gerard 1987; Koehl and Alberte 1988). Researchers have observed that the characteristic morphology of ruffled blades promotes flapping, which has also been reported to increase nutrient uptake (e.g. Koehl and Alberte 1988). Flapping has the potential to enhance mass transfer to and from the seaweed blade surface by periodically 'stripping' away the DBL and fostering its 'renewal' (Huang et al. 2011).

The role of morphological variation in seaweed growth has been of interest especially with respect to nutrient uptake (e.g. Gerard and Mann 1979; Koehl and Alberte 1988; Hurd et al. 1996; Stevens et al. 2003; Koehl et al. 2008; Hurd and Pilditch 2011). For example, Koehl et al. (2008) reported that undulated morphology of blades of Nereocystis luetkeana from sheltered sites increased drag, but at the same time enhanced light interception and bicarbonate uptake at flow velocities lower than $1 \mathrm{~m} / \mathrm{s}$. Hurd and Pilditch (2011) tested blades of Macrocystis pyrifera at a range of low flow velocities $(0.008-0.045 \mathrm{~m} / \mathrm{s})$ and estimated the thickness of the DBL via measurements of oxygen concentration from an 
$\mathrm{O}_{2}$ micro-optode. They concluded that the thickness of the DBL declined as flow velocity increased, although the benefits of ruffled morphology in terms of nutrient uptake were not fully clear. Indeed, a debate continues on whether ruffled morphology enhances nutrient uptake in seaweeds. To shed a light on this issue, there is a need for a better understanding of the processes governing the DBL and its renewal (Hurd 2000). A major difficulty in performing direct measurements of the thickness of the DBL is that seaweed blades are not stationary in their natural environment. This limits the application of novel techniques such as $\mathrm{O}_{2}$ micro-optode to cases in which blades do not move, i.e. at very low flow velocities which may not be representative of conditions commonly found in field settings.

Water motion is indeed crucial for seaweeds because it affects most abiotic and biotic factors driving seaweed growth (Hurd 2000). On the one hand, water motion ensures nutrient delivery to the seaweed surface and light availability for the blades; on the other hand, it is a source of hydrodynamic forces that affect seaweed survival. The understanding of the forces exerted by the flow on seaweeds is still incomplete. Most of the previous studies investigated the mean drag force linking it to the mean flow velocity (e.g. Boller and Carrington 2006), neglecting the role of the inherent fluctuations in drag and flow velocities due to waves and turbulence. This way seaweed dynamics cannot be characterised comprehensively as important information about the extreme forces exerted by the flow on the seaweed is not accounted for (e.g. Denny 1994). Buck and Buchholz (2005) measured the drag force experienced by Saccharina latissima for a range of flow velocities by towing seaweed blades in a tank with still water. This approach does not necessarily provide an estimate of the drag coefficient that is representative of the natural conditions, because there is no 'background' turbulent flow in the tank and therefore a 'turbulence' factor in blade reconfiguration is absent. In a towing tank, only the reconfiguration powered by the vortices shed by blades occurs, but this is likely to be a secondary factor in blade dynamics compared to the role of incoming turbulence (Vettori and Nikora 2018).

In the study reported here, we investigated the interactions between single blades of S. latissima and unidirectional turbulent flow using experiments in an open-channel flume that involved measurements of flow velocities, drag force experienced by blades, and their movements and reconfiguration. The main objectives of the present paper are: (1) to investigate how seaweed blades respond to a range of hydraulic conditions in terms of reconfiguration and drag force; (2) to obtain estimates of the drag coefficient $C_{d}$ of seaweed blades for a range of hydraulic conditions; (3) to improve understanding of the mechanisms driving blade dynamics; and (4) to obtain estimates of the thickness of the DBL $\delta_{d}$ at seaweed blade surfaces for a range of hydraulic conditions. The results of this study provide some insights on the physical processes occurring at a blade scale and on how blades can adjust to different hydraulic conditions. Mechanisms of scale-dependent dynamic interactions between blades and turbulent eddies have direct implications for seaweed growth, acclimation, and survival and thus should be useful for the development of bio-physical models, environmental assessments, and design of seaweed farms.

\section{Materials and methods}

\section{Seaweed collection and storage}

Samples of S. latissima were collected on 10th February 2015 from long-lines of an aquaculture facility (Loch Fyne Oysters Limited; Loch Fyne, Scotland, UK; 56.08 N, $5.28 \mathrm{~W}$ ). Hydraulic conditions within Loch Fyne were assessed by analysing a 3-month time series (http://www. bodc.ac.uk) recorded with a current meter $10 \mathrm{~km}$ North East of the collection site (Vettori and Nikora 2017). A total of 80 seaweed samples were transported to the University of Aberdeen on the day of collection, and then stored in an aerated 1251 tank filled with seawater. The tank was kept outdoor so that water temperature was similar to ambient temperature and seaweeds were exposed to natural light conditions. Due to the lack of flow recirculation, seawater in the tank was changed every 3-4 days. All samples were used within 13 days of collection.

\section{Laboratory equipment}

\section{Facility}

Experiments were conducted in a tilting recirculating flume with glass sidewalls in the Fluid Mechanics Laboratory of the University of Aberdeen (Scotland, UK). The flume is $12.5 \mathrm{~m}$ long, with a rectangular cross section $0.3 \mathrm{~m}$ wide and $0.45 \mathrm{~m}$ deep. Flow uniformity was assessed by monitoring the water depth and surface level along the flume. The flume bed was covered with a canopy of artificial grass (canopy height $=4.4 \mathrm{~cm}$, Fig. 1), which was not directly related to this study, but enhanced turbulence intensity to values close to those found in tidal flows (Vettori and Nikora 2018). Since the recirculating flume could not run with saltwater, freshwater had to be used in the experiments.

\section{Acoustic doppler velocimeters}

Flow velocities were measured using two Acoustic Doppler Velocimeters (ADVs; Vectrino+, Nortek AS, Rud, Norway). The recorded velocity vector components represent spatially-averaged values within a sampling volume 


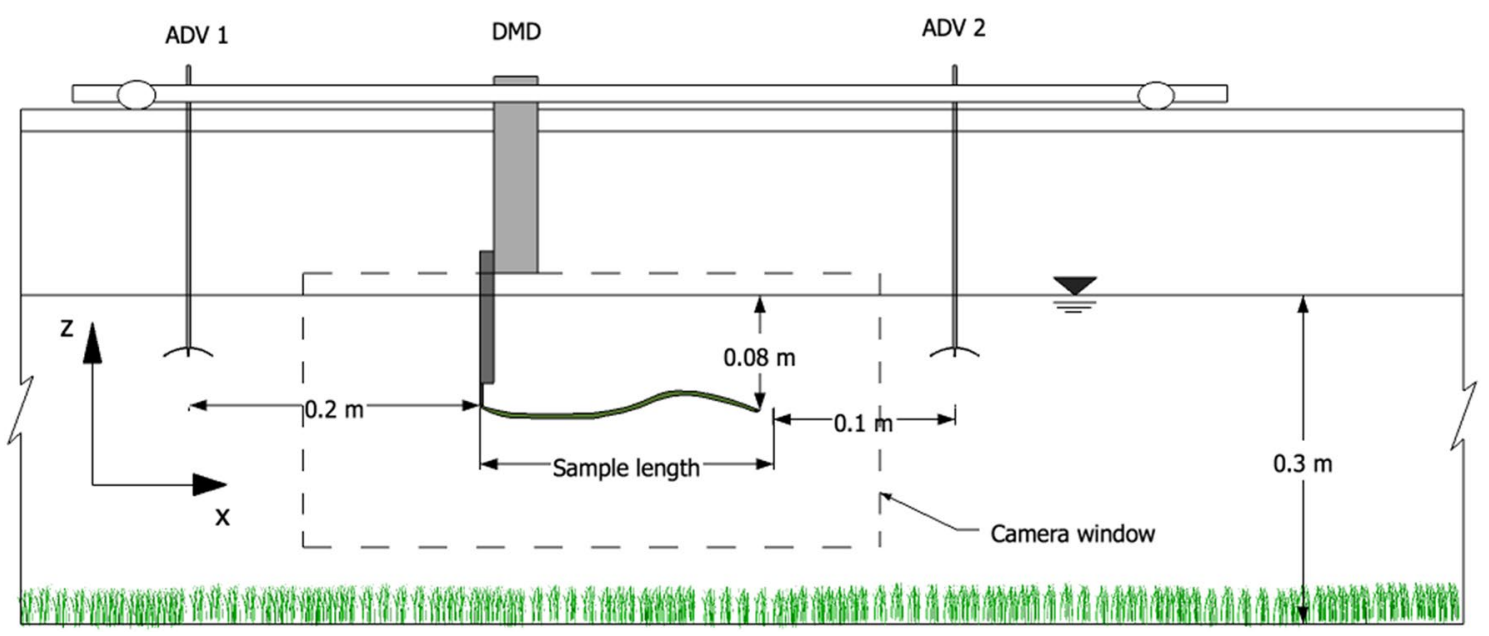

Fig. 1 Side view of the experimental setup for investigation of flowseaweed blade interactions (not to scale). The flume bed was covered with a canopy of artificial grass that enhanced turbulence intensity to

of $\sim 0.25 \mathrm{~cm}^{3}$ positioned $5 \mathrm{~cm}$ below the acoustic transmitter to provide undisturbed measurements (Nortek 2004). Both instruments recorded at a sampling frequency of $100 \mathrm{~Hz}$. To maximise signal-to-noise ratio in ADV measurements, small amounts of the seeding material (hollow glass spheres with mean diameter $10 \mu \mathrm{m}$ ) were mixed with water at concentrations less than $5-10 \mathrm{mg} / \mathrm{l}$. No visible effects of the seeding material on the blade performance were noted.

\section{Drag measurement device}

The drag force acting on samples was measured using a Drag Measurement Device (DMD; Vettori and Nikora 2018) which consists of a $1 \mathrm{~N}$ or $5 \mathrm{~N}$ SMD S100 thin film load cell (Strain Measurement Devices, Chedburgh, England) connected to a data acquisition scanner (Vishay PG6100) controlled by dedicated software (StrainSmart, Vishay Precision Group, Malvern, USA). During experiments, a seaweed blade was attached to the load cell via a tapered rod in such a way that the instrument would measure only the force component parallel to the main flow. The rod was protected by a hydrofoil-shaped brass pipe so that the rod area exposed to the flow and the effects of the pipe on the flow were minimised (Figure 2 in Vettori and Nikora 2018). The DMD recorded at a frequency of $200 \mathrm{~Hz}$ and was synchronised with the ADVs by means of a high-voltage card installed in the data acquisition scanner.

\section{Video recording}

Seaweed blade motion was recorded using a full-HD camera (HMX-R10BP, Samsung, Seoul, South Korea) positioned next to the glass wall of the flume. The videos were recorded values close to those found in tidal flows (Vettori and Nikora 2018). Flow direction is from left to right (from Vettori and Nikora 2018)

with a frame rate of $25 \mathrm{~Hz}$. The synchronisation of the videos with the data collected by the ADVs and DMD was achieved during the video processing phase by identifying the frame in which a light emitting diode (LED) included in the sampling window turned on (Fig. 3a). Being powered by the same trigger used to start data recording with the other instruments, the LED would turn on synchronously when the ADVs and DMD records started.

\section{Experimental setup and procedure}

Prior to experiments, seaweed blades were subdivided into 5 groups (i.e. G1-G5) according to their length, spanning from 150 to $650 \mathrm{~mm}$ with $100 \mathrm{~mm}$ intervals (e.g. $250-349 \mathrm{~mm}$, $350-449 \mathrm{~mm}$, and so on). Three blades as morphologically similar to each other as possible were selected from each group for flume experiments; their morphological characteristics are given in Table 1. Only seaweed blades showing no signs of deterioration or damage were used in the experiments. Because of the potential effects of freshwater (e.g. Hurd et al. 2014) and hydraulic conditions on seaweeds, each blade within a group was tested only once, in one of the flow scenarios listed in Table 2. Note that the mean flow velocity in flow scenario 'Run 1' (Table 2) was similar to the typical flow velocity observed at the collection site according to the historical time series available (Vettori and Nikora 2017).

During the experiments, a seaweed blade was kept in the central section of the flume to minimise inlet and outlet effects on the background flow. All experiments were conducted with unidirectional flow at quasi-uniform flow conditions, with the water depth $H$ set to $0.3 \mathrm{~m}$ to maximise seaweed blade freedom of motion. Preliminary 
Table 1 List of seaweed blades used in the experiments and their main morphological characteristics

\begin{tabular}{lllllll}
\hline Group & Flow scenario & $l(\mathrm{~mm})$ & $w_{\max }(\mathrm{mm})$ & $t(\mathrm{~mm})$ & $A_{\text {side }}\left(\mathrm{mm}^{2}\right)$ & $A_{\text {proj }}\left(\mathrm{mm}^{2}\right)$ \\
\hline G1 & Run 1 & 196 & 62 & $0.12-0.43$ & $0.7 \times 10^{4}$ & $0.7 \times 10^{4}$ \\
& Run 2 & 160 & 63 & $0.15-0.47$ & $0.6 \times 10^{4}$ & $0.6 \times 10^{4}$ \\
& Run 3 & 205 & 68 & $0.13-0.42$ & $0.8 \times 10^{4}$ & $0.8 \times 10^{4}$ \\
G2 & Run 1 & 275 & 77 & $0.13-0.65$ & $1.3 \times 10^{4}$ & $1.2 \times 10^{4}$ \\
& Run 2 & 285 & 82 & $0.12-0.52$ & $1.4 \times 10^{4}$ & $1.4 \times 10^{4}$ \\
& Run 3 & 310 & 81 & $0.15-0.91$ & $1.7 \times 10^{4}$ & $1.5 \times 10^{4}$ \\
G3 & Run 1 & 424 & 132 & $0.13-0.93$ & $3.1 \times 10^{4}$ & $2.8 \times 10^{4}$ \\
& Run 2 & 444 & 134 & $0.13-0.7$ & $3.1 \times 10^{4}$ & $2.9 \times 10^{4}$ \\
& Run 3 & 419 & 124 & $0.12-0.76$ & $2.7 \times 10^{4}$ & $2.5 \times 10^{4}$ \\
G4 & Run 1 & 519 & 181 & $0.14-0.83$ & $5.5 \times 10^{4}$ & $4.5 \times 10^{4}$ \\
& Run 2 & 548 & 174 & $0.15-0.82$ & $5.7 \times 10^{4}$ & $4.7 \times 10^{4}$ \\
& Run 3 & 516 & 17 & $0.21-1.54$ & $6.7 \times 10^{4}$ & $5.6 \times 10^{4}$ \\
G5 & Run 1 & 570 & 127 & $0.11-0.85$ & n. a. ${ }^{\mathrm{a}}$ & $3.6 \times 10^{4}$ \\
& Run 2 & 599 & 143 & $0.13-1.82$ & n. a. ${ }^{\mathrm{a}}$ & $4.9 \times 10^{4}$ \\
& Run 3 & 601 & 118 & $0.09-1.21$ & n. a. ${ }^{\mathrm{a}}$ & $4.1 \times 10^{4}$ \\
\hline
\end{tabular}

$l$ length, $w_{\max }$ maximum width, $t$ thickness range, $A_{\text {side }}$ one-side wetted surface area, $A_{\text {proj }}$ one-side projected surface area of seaweed blades

${ }^{a}$ One-side wetted surface area could not be estimated for these blades, because their dimensions exceeded those of the light table used to take photos of the test samples from which surface areas were extracted

\begin{tabular}{lllllll}
\hline & $H(\mathrm{~m})$ & $Q\left(\mathrm{~m}^{3} / \mathrm{s}\right)$ & $U_{m}(\mathrm{~m} / \mathrm{s})$ & $U_{u p}(\mathrm{~m} / \mathrm{s})$ & $R e_{H}=H U_{m} / \nu$ & $R e_{l}=l U_{u p} / \nu$ \\
\hline Run 1 & 0.3 & $7 \times 10^{-3}$ & 0.09 & 0.1 & $0.27 \times 10^{5}$ & $(0.2-0.6) \times 10^{5}$ \\
Run 2 & 0.3 & $21.5 \times 10^{-3}$ & 0.29 & 0.33 & $0.87 \times 10^{5}$ & $(0.5-2.0) \times 10^{5}$ \\
Run 3 & 0.3 & $36 \times 10^{-3}$ & 0.48 & 0.55 & $1.44 \times 10^{5}$ & $(1.1-3.3) \times 10^{5}$ \\
\hline
\end{tabular}

Note that five blades, one for each group introduced in Table 1, were tested at each flow scenario

$H$ water depth, $Q$ flow rate, $U_{m}$ cross-sectional average velocity, $U_{u p}$ mean approach velocity in front of the seaweed blade, $R e_{H}$ Reynolds number, $R e_{l}$ blade Reynolds number, $\nu$ kinematic viscosity of water
Table 2 Hydraulic conditions of flow scenarios used in the experiments measurements were performed to obtain flow characteristics along the vertical profile. Using these data, the region with quasi-homogenous turbulence quantities and vertically-uniform mean flow velocity was identified to be within the upper $0.15-0.17 \mathrm{~m}$. Based on these findings and technical limitations inherent to the instrumentation, we positioned the seaweed blade (the point at which it was attached to the DMD) and the centre of ADV sampling volumes at $0.22 \mathrm{~m}$ above the channel bed, i.e., in the middle of the quasi-homogeneous flow layer. In order to measure velocities and turbulence characteristics of the undisturbed (approach) flow and in the wake of the seaweed blade, one ADV was positioned $0.2 \mathrm{~m}$ upstream of the blade clamped end while the second ADV was located $0.1 \mathrm{~m}$ downstream of its free end (Fig. 1). Seaweed blades were tested at three flow scenarios defined as 'Run 1', 'Run 2', and 'Run 3' (Table 2). In our work we employed the Reynolds number $R e_{H}$, defined using the water depth and the cross-sectionally-averaged flow velocity (i.e. $R e_{H}=H U_{m} / \nu$, where $H$ is the water depth, $U_{m}$ is the cross-sectionally-averaged flow velocity, and $\nu$ is kinematic viscosity of water), and the blade Reynolds number $R e_{l}$, determined using the blade length $l$ and mean approach velocity $U_{u p}$ in front of the blade (i.e. $\operatorname{Re}_{l}=l U_{u p} / v$ ).

The measurement duration in the experiments had to be defined depending on seaweed adjustment to the environmental conditions in the flume setting, particularly in relation to flow properties and freshwater effect. For this reason, a preliminary $2 \mathrm{~h}$ long test was conducted with a seaweed blade (not listed in Table 1), with the instruments recording as in the standard configuration. The data revealed that mean value and standard deviation of the drag force reduced significantly in the first 50 min of the measurements and then stabilised (Fig. 2), likely reflecting acclimation to hydraulic conditions and probably biomechanical changes of the blade tissue as a result of being in the freshwater environment. Therefore, the full duration of the experiments was set to be $80 \mathrm{~min}$, which seemed an adequate period to cover the whole period of seaweed blade adjustments to the experimental conditions. 


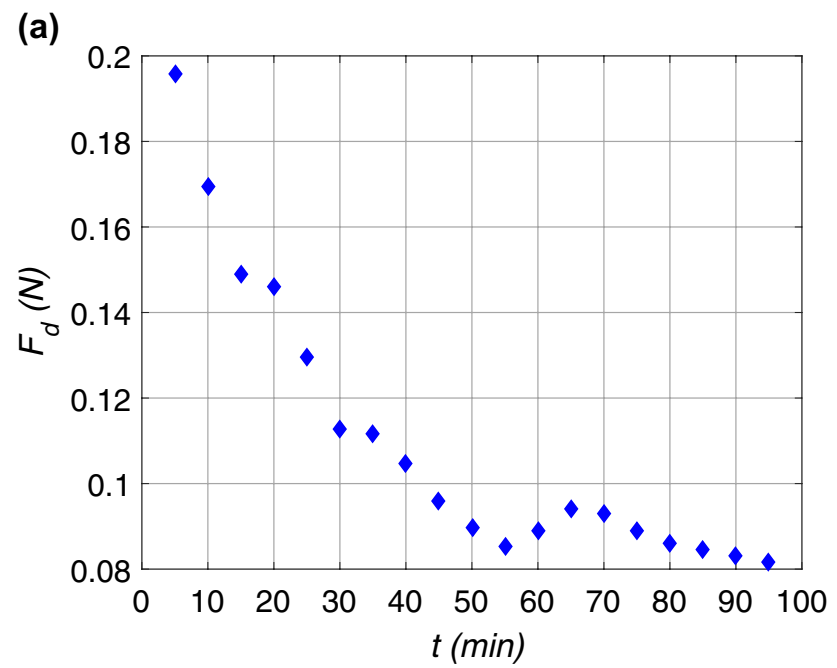

Fig. 2 Dynamics of the mean (a) and standard deviation (b) of the drag force experienced by a seaweed blade at a preliminary test designed to identify the duration of the experiments conducted with

During all experiments, the digital camera recorded continuously at $25 \mathrm{~Hz}$, while the DMD and the ADVs measured 8 'window' records of 10 min each at $200 \mathrm{~Hz}$ and $100 \mathrm{~Hz}$, respectively. Between each 10-min window record about 30 s were lost to re-set the DMD and ADVs via dedicated software. This was necessary to prevent potential errors imposed by the measurement system during data collection for longer recording periods.

\section{Data analysis}

Standard errors associated with the mean values and variances of streamwise flow velocity and drag force were quantified following Garcia et al. (2006). The average relative standard error of $U$ was $2.1 \%$, with a maximum of $7.3 \%$ (for blade G5 at flow scenario 'Run 1'). For the variance $\sigma_{u}^{2}$ the maximum relative standard error was $5.7 \%$ (for blade G5 at flow scenario 'Run 1'), with an average of 3.1\%. For the drag force, the standard errors associated with the mean value $F_{d}$ and variance $\sigma_{d}^{2}$ did not exceed $10^{-4} \mathrm{~N}$ and $10^{-7} \mathrm{~N}$, respectively.

\section{Relevant statistical quantities}

In the current study we make use of statistical quantities of two types: (1) conventional moments of probability distributions such as mean $X$, variance $\sigma_{x}^{2}$ (and standard deviation, $\sigma_{x}$ ), skewness (Eq. 1), and kurtosis (Eq. 2); and (2) spectral characteristics such as spectral densities, coherence functions (Eq. 3), and gain factors (Eq. 4). We consider the following records which are interpreted as realisations of random functions: flow velocities $(u, v, w)$ (b)

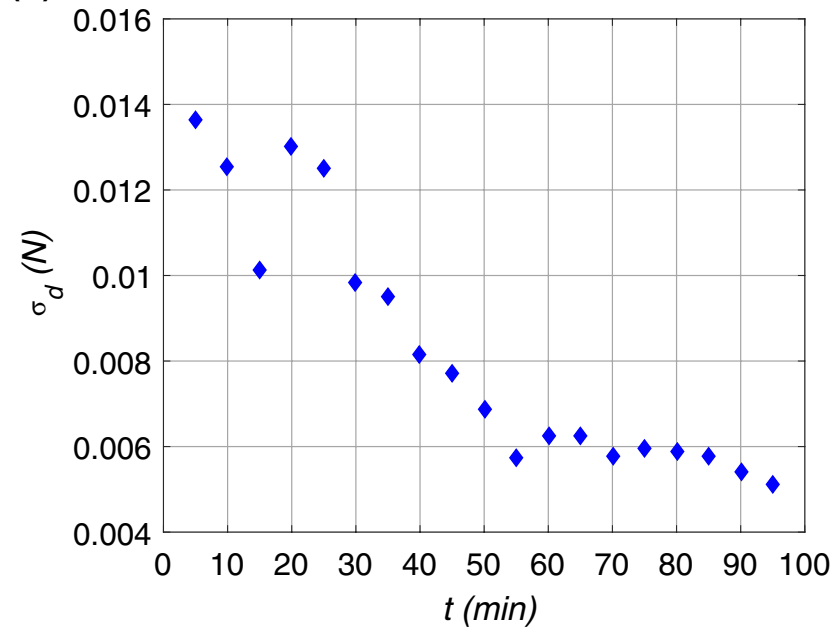

seaweed blades listed in Table 1. Values are computed for 10-min time windows with $50 \%$ overlap

in $x, y$, and $z$ directions upstream and downstream of a blade, the drag force $\left(f_{d}\right)$, and the vertical velocity of a blade $\left(w_{b}\right)$. The skewness and kurtosis of the records were estimated with:

$S k_{x}=\left[\frac{1}{n}\left(\sum_{i=1}^{n} x_{i}-X\right)^{3}\right] / \sigma_{x}^{3}$

$K u_{x}=\left[\frac{1}{n}\left(\sum_{i=1}^{n} x_{i}-X\right)^{4}\right] / \sigma_{x}^{4}-3$.

The skewness provides information about the asymmetry of the probability distribution in terms of its direction (sign of the skewness) and magnitude (its value). The kurtosis describes the peakedness of the probability distribution compared with a Gaussian distribution. Both statistical moments are equal to 0 for a Gaussian distribution (e.g. Davidson 2015).

We also use time series analysis, specifically spectral analysis, to investigate fluctuations from the long-term means of the measured variables. The power spectral density function (or spectrum) $S_{x}(f)$ of a generic record $x$ was computed using Fast Fourier Transform (FFT) after de-trending the measured time series of $x$. The spectra represent a measure of the energy density distribution across various frequencies $f$ (or time periods $1 / f$ ), i.e. how much energy is contained within a narrow band of frequencies corresponding to turbulent eddies of a certain size. 
To explore possible associations at different frequencies between two fluctuating variables $x$ and $y$ (e.g. drag force and approach velocity), the coherence function $\gamma_{x y}^{2}(f)$ and the gain factor $\left|H_{x y}(f)\right|^{2}$ were used (Bendat and Piersol 2011). These two quantities are defined as:

$\gamma_{x y}^{2}(f)=\frac{\left|S_{x y}(f)\right|^{2}}{S_{x}(f) S_{y}(f)}$

$\left|H_{x y}(f)\right|^{2}=\frac{S_{y}(f)}{S_{x}(f)}$

where $S_{x y}(f)$ is a cross-spectrum between signals $x$ and $y$, and $f$ is frequency (e.g. Bendat and Piersol 2011). The coherence function $\gamma_{x y}^{2}(f)$ can be interpreted as a squared correlation coefficient between signals $x$ and $y$ at a particular frequency $f$; it satisfies the condition $0 \leq \gamma_{x y}^{2}(f) \leq 1$. The gain factor $\left|H_{x y}(f)\right|^{2}$ indicates how a magnitude of the signal $x$ at a frequency $f$ is amplified in the signal $y$. A specific example of the gain factor is the fluid dynamic admittance $\left|\chi_{f l}(f)\right|^{2}$ (Eq. 5) that indicates the role of eddies of different frequencies in the generation of drag fluctuations. The fluid dynamic admittance can be defined by using the classical drag formulation (e.g. Batchelor 1967) and the Reynolds averaging rule (e.g. Monin and Yaglom 1971), and it is expressed as (Naudascher and Rockwell 2005; Dwivedi et al. 2010):

$\left|\chi_{f l}(f)\right|^{2}=\frac{1}{4}\left(\frac{U_{u p}}{F_{d}}\right)^{2} \frac{S_{d}}{S_{u-u p}}$

where $U_{u p}$ is mean flow velocity upstream of a blade, $F_{d}$ is mean drag force, $S_{d}$ is the drag spectrum, and $S_{u-u p}$ is the spectrum of the streamwise flow velocity upstream of a blade.

\section{Flow velocities}

The raw ADV data are inherently affected by measurement errors, including erroneous spikes in the data that can heavily bias the estimation of turbulence parameters (e.g. Goring and Nikora 2002). Consequently, ADV data were despiked using the phase-space threshold method (Goring and Nikora 2002), modified by Parsheh et al. (2010) and named as mPST. The last good value approach (Goring and Nikora 2002) was used to replace spurious data points detected by mPST. Then, the standard statistical moments (mean, variance, skewness, and kurtosis) and the spectrum were evaluated for each velocity component.

\section{Drag force}

As a consequence of the DMD design, the drag force recorded during the experiments included the contributions from both the seaweed blade and the rod tip to which the blade was attached. Nevertheless, no correction was applied for the drag force experienced by a blade because of potential non-linear interference between fluctuating contributions from the blade and the rod tip. This interference can lead to the difference between the sums of individual contributions obtained in isolation and when measured together. Our preliminary assessments showed that the rod contribution to the measured drag can become noticeable only for the smallest blades.

Since frontal projected area of a blade was found to be uncorrelated with the drag force experienced by the blade (Vettori 2016), the (mean) drag coefficient $C_{d}$ was estimated by applying a 'static' approach (Statzner et al. 2006), i.e.:

$C_{d}=F_{d} /\left(0.5 \rho_{w} A_{w e t} U_{u p}^{2}\right)$

where $\rho_{w}$ is water density, and $A_{\text {wet }}$ is wetted surface area of a blade. This conventional form of the drag coefficient is supplemented in our analysis with the 'instantaneous drag coefficient' defined as:

$c_{d}\left(t_{i}\right)=f_{d}\left(t_{i}\right) /\left[0.5 \rho_{w} A_{w e t} u_{u p}^{2}\left(t_{i}\right)\right]$

where $f_{d}\left(t_{i}\right)$ and $u_{u p}\left(t_{i}\right)$ are the instantaneous values of the drag force and upstream streamwise flow velocity, respectively, and $t_{i}$ is time instant when the measurements were taken. Our data showed that the estimates of $C_{d}$ from Eq. (6) and as a mean of instantaneous $c_{d}$ of Eq. (7) are statistically indistinguishable. Therefore, below we will use the same symbol $C_{d}$ when considering the mean drag coefficients.

It is also worth noting that some micro-mechanical vibrations associated with the flume, instrumental carriage, and DMD affected the measured drag force signals. These microvibrations are responsible for apparently spurious peaks displayed by the spectra of drag force (Fig. 6a) at several frequencies higher than $5 \mathrm{~Hz}$. However, the overall effect of these micro-vibrations on the variance of the drag force is negligible (i.e. the area under the peaks is negligible compared to the total area of the whole spectrum).

\section{Blade motion}

Video processing was conducted using MATLAB ${ }^{\circledR}$ image processing tools. Each frame (Fig. 3a) was converted to black and white and cropped to exclude the irrelevant objects. This approach allowed achieving a reduction of both the amount of data to be processed and the chances of 


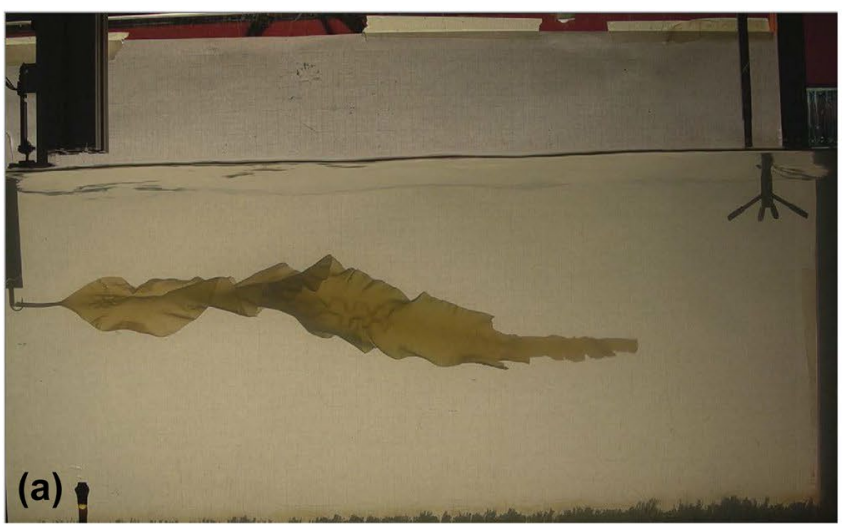

Fig. 3 a A frame extracted from a video recorded during the test of sample G3 at flow scenario 'Run 3'. On the bottom left corner, the light emitting diode (LED) used to achieve synchronisation between the video and the other instruments is visible. b Output from a frame

false data points to be detected. The Canny edge detector algorithm (Canny 1986) was then employed for extracting the vertical positions of the seaweed blade from each frame (Vettori 2016). After the edge detection, each video frame was divided into a number of vertical interrogation regions 10 pixels wide, and a 'centroid' was identified in each vertical region as the centre between the upper and lower boundary in that region (Fig. 3b). This way, time series of vertical positions $z_{b}(t)$ of the blade (i.e. of the centroids) were obtained for various locations along the blade. The point at which the blade was attached to the DMD was used as the origin of the vertical coordinate.

The time series of the blade vertical velocity $w_{b}(t)$ were computed using the time series of the vertical position $z_{b}(t)$ of the blade centroid as:

$w_{b}\left(t_{j}\right)=\frac{z_{b}\left(t_{j}\right)-z_{b}\left(t_{j-1}\right)}{\Delta \tau}$

where $w_{b}\left(t_{j}\right)$ is estimated at time $t_{j}$, and $\Delta \tau$ is time interval between two consecutive samples (e.g. $t_{j}-t_{j-1}$ ).

\section{Results}

\section{Blade acclimation to the hydraulic conditions: drag force and reconfiguration}

All seaweed blades tested adjusted to the new conditions to which they were exposed during experiments in the flume facility; this adjustment concerned drag force and, marginally, blade dynamics. The mean value $F_{d}$, standard deviation $\sigma_{d}$, skewness $S k_{d}$, autocorrelation function, and the magnitude of the spectrum $S_{d}$ of the drag force decreased with time until they fully stabilised at around 20-30 min from

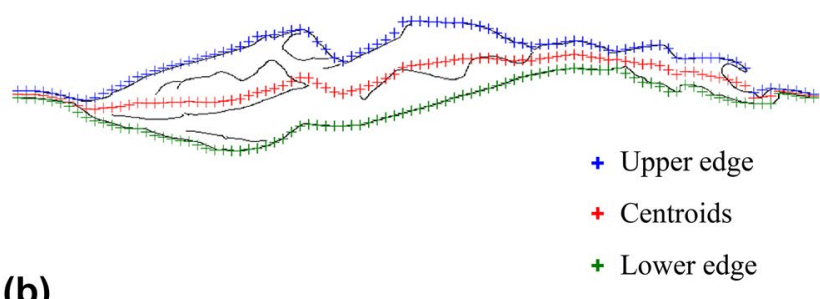

showing: all edges detected by the algorithm (black), blade upper edge (blue), blade lower edge (green) and blade centroids (red) (the shown frame refers to sample G2 at flow scenario 'Run 2') (Color figure online)

the beginning of the experimental runs. The general trends are valid for all blades tested and can be illustrated in Fig. 4, where the mean value $C_{d}$ and standard deviation $\sigma_{c d}$ of the instantaneous drag coefficient are plotted as a function of time. Note that in Fig. 4 we used the statistical moments of the instantaneous drag coefficient $c_{d}\left(t_{i}\right)$ rather than those of the instantaneous drag force $f_{d}\left(t_{i}\right)$, because the drag coefficient is a non-dimensional quantity and allows comparing blades of different dimensions. The reductions in $C_{d}$ and $\sigma_{c d}$ from the first 10-min record to the last record increased at higher mean flow velocities: e.g. in 'Run 1' both $C_{d}$ and $\sigma_{c d}$ showed an average reduction of $32 \%$ (averaged across all blade groups), whereas in 'Run 3' $C_{d}$ and $\sigma_{c d}$ declined by $43 \%$ and $55 \%$, respectively. The kurtosis $K u_{d}$ of the drag force, on the other hand, did not show any change in time.

Most parameters describing blade dynamics did not vary with time, apart from the standard deviation $\sigma_{z b}$ of the vertical position of the blade, which for some blades decreased from the beginning to the end of the experiment. The characteristics of the flow downstream of a blade appeared to be steady (i.e. statistical characteristics of velocities did not vary between 10-min records). Since the data of the drag force were not stationary throughout the experiments, we focus our analyses on the last 10-min of the records, after blade adjustment has been completed and all measured quantities became stationary (i.e. independent of time in statistical sense).

\section{Coupling between turbulence and fluctuations of drag force}

Both the mean $F_{d}$ and standard deviation $\sigma_{d}$ of the drag force increased with $U_{u p}$. The coefficient of variation $\sigma_{d} / F_{d}$ varied from 0.04 to 0.09 . Skewness $S k_{d}$ and kurtosis $K u_{d}$ of the drag force were close to 0 and were not affected by hydraulic 

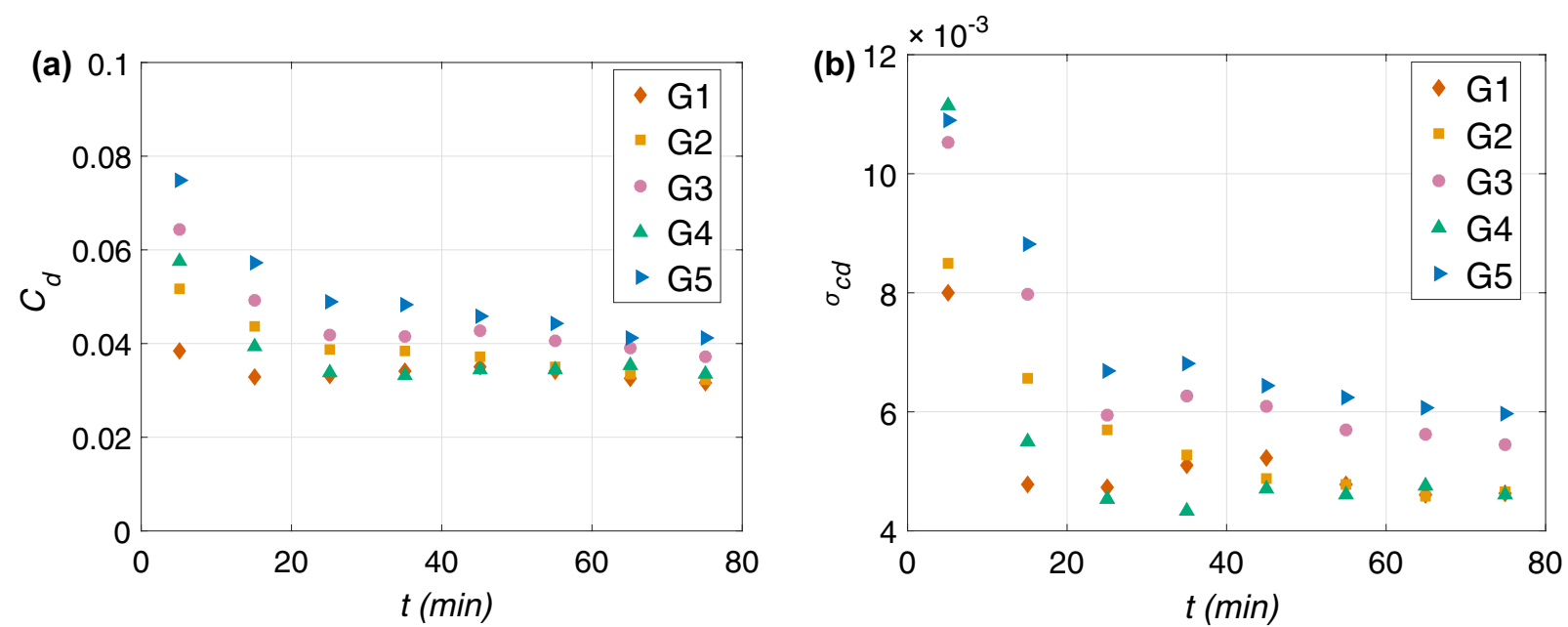

Fig. 4 Effect of time of exposure to experimental conditions on the (mean) drag coefficient (a) and its standard deviation (b). Both figures refer to flow scenario 'Run 2' (see Table 2), for a description of seaweed blades see Table 1

conditions, suggesting that the probability distribution of drag force fluctuations in all cases is close to Gaussian. Although each blade was tested at a single experimental run only, blades were of similar dimensions within each group (Table 1) and thus it was possible to estimate Vogel's exponent $\gamma, F_{d} \propto U_{u p}^{2+\gamma}$ (Vogel 1994). Vogel's exponent ranged between -0.6 and -0.2 , indicating that blades successfully reduced the drag force via reconfiguration. Because blades streamlined with the flow have often been modelled as flat plates (e.g. Nepf 2012), the mean drag coefficient $C_{d}$ of the blades was compared with those for flat plates (examined as a function of $R e_{l}$ in Fig. 5a). The obtained $C_{d}$ are higher than for laminar and turbulent boundary layers over equivalent (i.e. with same length) flat plates, although also showing a

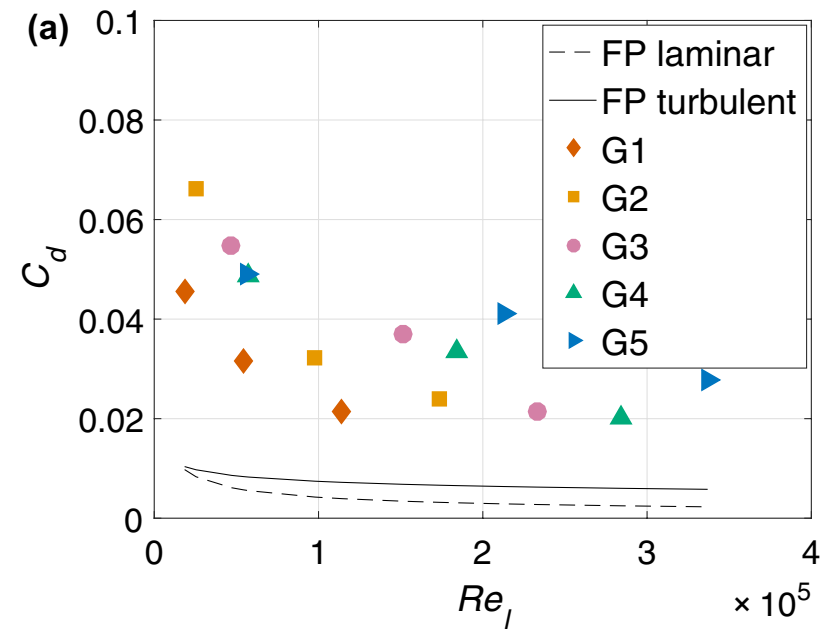

Fig. 5 The drag coefficient as a function of the blade Reynolds number $R e_{l}=l U_{u p} / \nu$ (a) and the Cauchy number $C_{y}=\rho_{w} U_{u}^{2} \beta^{3} /\left(E t_{m e d}^{3}\right)_{h}(\mathbf{b})$. The dashed line and the solid line in a are the drag coefficient for a similar decreasing trend (Fig. 5a). The drag coefficient for a laminar boundary layer over a flat plate (Eq. 9) was estimated according to the classical Blasius' equation while for the turbulent boundary layer the ' $1 / 5$ '-th law (Eq. 10) was used (e.g. Schlichting and Gersten 2000):

$C_{d-F P L}=1.328 / \sqrt{R e_{l}}$

$C_{d-F P T}=0.074 / R e_{l}^{1 / 5}$

The difference between the measurements and predicted drag coefficients for boundary layers (Fig. 5a) are likely due to the effects of ruffles and bullations present on the surface

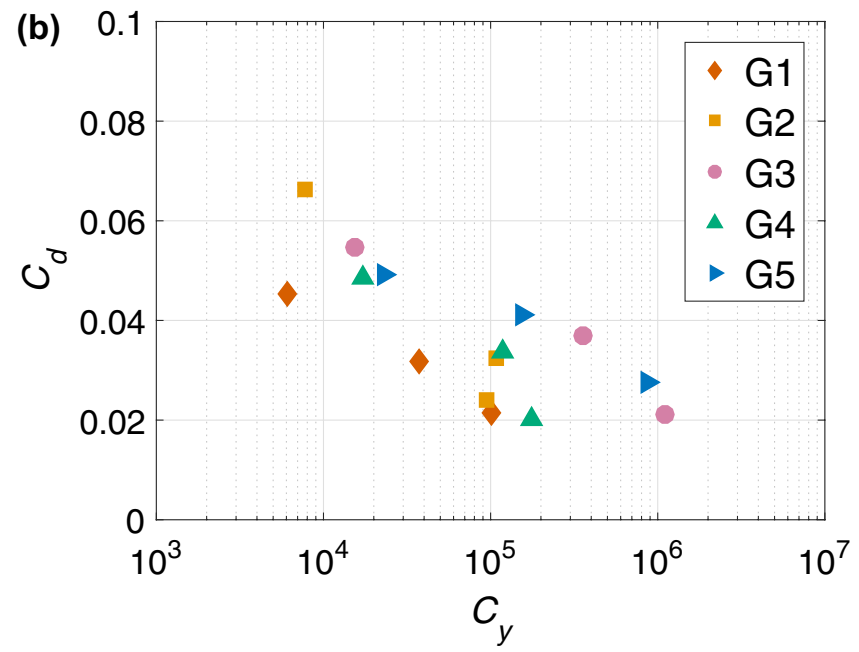

laminar boundary layer and a turbulent boundary layer over a flat plate, respectively 
of seaweed blades, upcoming turbulence, and specific shape of the blades. The blade Reynolds number in our experiments was always lower than the threshold at which the transition to turbulent boundary layer on smooth flat plates occurs (i.e. $R e_{l}=5 \times 10^{5}$, Schlichting and Gersten 2000). However, previous studies report such a transition to occur at much lower blade Reynolds number on seaweed blades, with mean flow velocity as low as $2 \mathrm{~cm} / \mathrm{s}$ (e.g. Hurd and Stevens 1997; Roberson and Coyer 2004). Thus, the boundary layer formed on our blades was unlikely to be laminar. We should highlight, in addition, that the blades operated in already turbulent ambient flow making formation of a laminar boundary layer even less possible.

A strong diminishing trend is also seen in plots of $C_{d}$ as a function of the Cauchy number $C_{y}=\rho_{w} U_{u p}^{2} l^{3} /\left(E t_{\text {mean }}^{3}\right)$, where $t_{\text {mean }}$ is the mean thickness of a blade, and $E$ is bending Young's modulus of the material of which blades are made (Fig. 5b). The Cauchy number is a descriptor of the deformation of a body due to the effect of the flow (de Langre 2008); it is defined as the ratio of the drag force associated with the flow to the flexural reactive force of the deformed body.

The magnitude of the spectrum $S_{d}$ of the drag force increased with increase in $U_{u p}$ and/or in the size of blades. To facilitate a comparison between different cases and the identification of common trends, a normalised $S_{d}$ using the variance $\sigma_{d}^{2}$ of the drag force was used in the analysis, i.e. $S_{d} / \sigma_{d}^{2}$. Except for different levels of the noise floor at high frequencies, caused by normalisation, spectra for all blades collapsed within narrow intervals of the normalised magnitudes $S_{d} / \sigma_{d}^{2}$ (Fig. 6a). The following spectral features should be noted: (1) at low frequencies the values of $S_{d} / \sigma_{d}^{2}$ decay

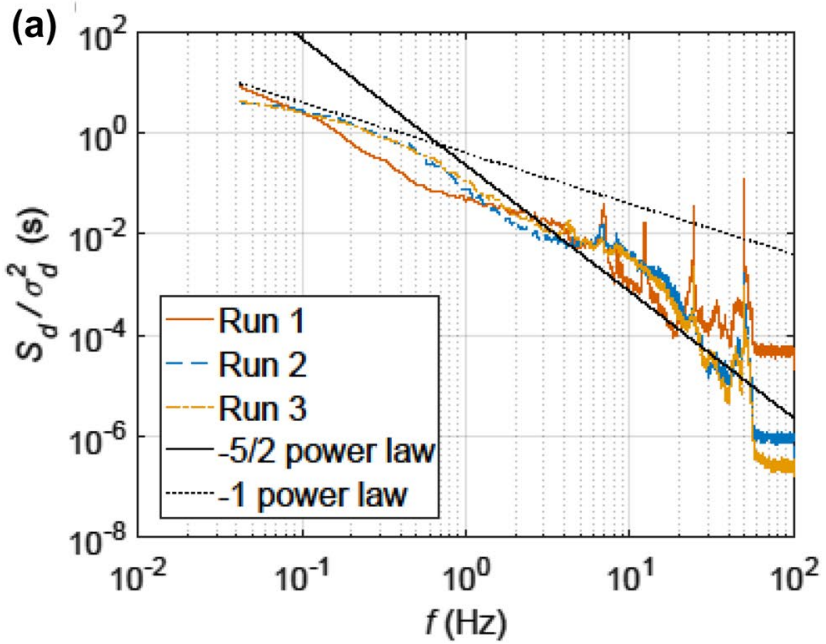

Fig. 6 a Spectra of the drag force normalised by drag variance; $\mathbf{b}$ fluid dynamic admittances as a function of the ratio of seaweed blade length $l$ to eddy wavelength $U_{u p} / f$. For each flow scenario (Run 1, Run 2 , Run 3), the curves represent averaged values across the data for with a spectral slope of -1 , similar to physical models of seaweed blades (Vettori and Nikora 2018); (2) at the intermediate frequencies the spectral slope corresponds to approximately $-5 / 2$, similar to freshwater plants (Siniscalchi and Nikora 2012); and (3) at high frequencies the spectra are characterised by a localised 'plateau' region, followed by a steep decrease. Note that the regions within which -1 and $-5 / 2$ spectral slopes hold are shifted to higher frequencies as $U_{u p}$ increases. The sharp localised peaks at frequencies higher than $5 \mathrm{~Hz}$ are most likely associated with mechanical micro-vibrations of the facility and are not features of the blade dynamics. The fluid dynamic admittance $\left|\chi_{f l}(f)\right|^{2}$ for seaweed blades are very similar to the fluid dynamic admittance for a simple supported cylinder in axial turbulent flow (Naudascher and Rockwell 2005). Curves are characterised by a plateau followed by a region of decline (that represents the contribution of the first mode of vibration), a local maximum at an intermediate frequency (representing the contribution of the second mode of vibration), and then a steep decrease (Fig. 6b).

The influence of the fluctuations of the upstream streamwise velocity $u_{u p}$ on the drag fluctuations was assessed via analysis of the coherence function $\gamma_{u-d}^{2}$ between $u_{u p}$ and the drag force (Fig. 7a). The fluctuations in the drag force were strongly associated with fluctuations of $u_{u p}$ at low frequencies. This is indicated by high values of $\gamma_{u-d}^{2}$ for a range of $f l / U_{u p}$ (that represents the ratio of seaweed blade length $l$ to the eddy wavelength $U_{u p} / f$ ), up to 2 (Fig. 7a). The fluctuations between the upstream vertical velocity $w_{u p}$ and the drag force were also correlated at low frequencies (with maximum values of $\gamma_{w-d}^{2}$ up to 0.4 ), probably reflecting a strong

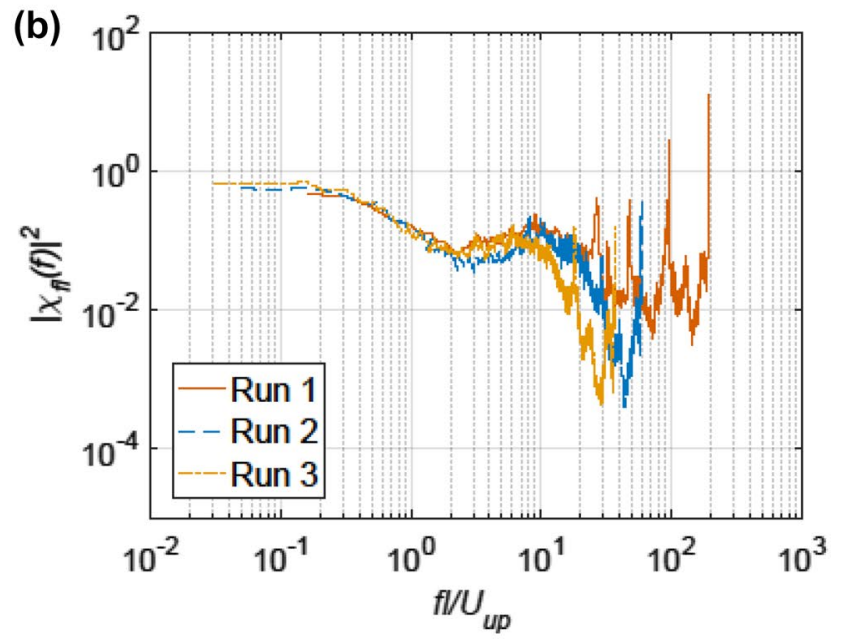

five blades. Note that the high-magnitude spurious peaks at frequencies higher than $5 \mathrm{~Hz}$ are caused by mechanical micro-vibrations of the facility 


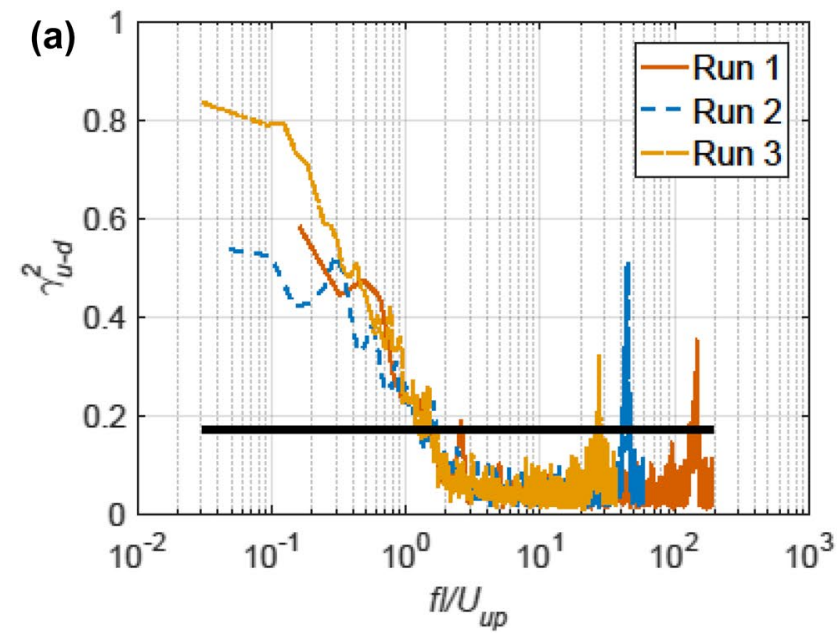

Fig. 7 Coherence functions between the streamwise flow velocity upstream of seaweed blade and the drag force (a), and between the vertical flow velocity upstream of seaweed blade and the blade vertical velocity at the blade free end (b) as a function of the ratio of seaweed blade length $l$ to eddy wavelength $U_{u p} / f$. For each flow scenario

correlation between the streamwise and vertical velocity components. As the mean flow velocity increased, so did the magnitudes of $\gamma_{u-d}^{2}$ (Fig. 7a). Higher magnitudes of $\gamma_{u-d}^{2}$ for individual blades relate to smaller blades (not shown here).

\section{Coupling between turbulence and blade dynamics}

The amplitude of oscillations of blade vertical position $z_{b}$ and blade vertical velocity $w_{b}$ increased along the blade towards its free end. Interestingly, their standard deviations $\sigma_{z b}$ and $\sigma_{w b}$ were relatively similar when comparing blades of different lengths, although they increased with the mean flow velocity. The mean blade vertical position, the mean blade vertical velocity, skewness and kurtosis of $z_{b}$ and $w_{b}$ were close to 0 along the blade. The near-zero values of skewness and kurtosis suggest that probability distributions of $z_{b}$ and $w_{b}$ fluctuations were close to Gaussian. The free ends of the seaweed blades were selected to be representative for a detailed spectral analysis, as: (1) both $z_{b}$ and $w_{b}$ showed the highest correlations with the upstream vertical flow velocity at the blade free end; (2) blades showed the maximum excursion at their free end; and (3) spectrum of blade vertical position was self-similar along the blade (i.e. the properly scaled spectra obtained at different locations collapsed).

The normalised spectra $S_{w b} / \sigma_{w b}^{2}$ exhibit a spectral 'hill' which is localised within a well-defined range of $f / U_{u p}$ between 0.2 and 3 (Fig. 8a). Complementary information can be obtained by analysing the gain factor $|H(f)|^{2}=S_{w b} / S_{w-u p}$ of the upstream vertical velocity and the blade vertical

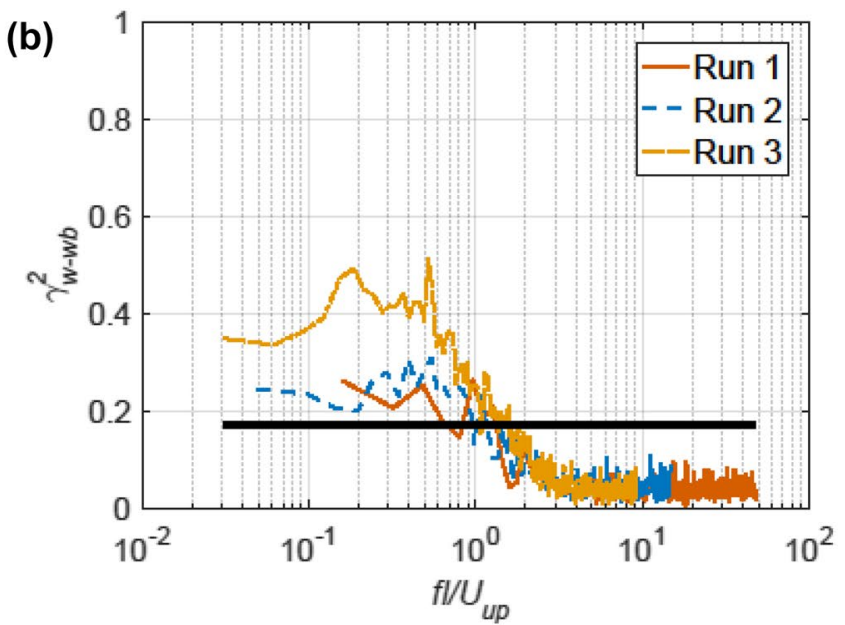

(Run 1, Run 2, Run 3), the curves represent averaged values across the data for five blades. The thick dark horizontal line represents the $1 \%$ significance level of the coherence function calculated according to Shumway and Stoffer (2000)

velocity (Fig. 8b). Three main regions can be identified in $|H(f)|^{2}$ : (1) region of large eddies (i.e. $f / U_{u p}<0.2$ ) which were not heavily involved in the blade motions (low $\left.|H(f)|^{2}\right)$; (2) region of intermediate size eddies (i.e. $0.2<f / / U_{u p}<3$ ) that control blade dynamics (high $|H(f)|^{2}$ ); and (3) region of small eddies (i.e. $f / U_{u p}>3$ ) showing significant association with the blade movements (relatively high $|H(f)|^{2}$ ), likely caused by eddy shedding effect.

The coherence function $\gamma_{w-w b}^{2}$ between $w_{u p}$ and $w_{b}$ was above the significance level for a range of low frequencies and was dependent on the hydraulic conditions (Fig. 7b). The coherence function $\gamma_{w-w b}^{2}$ was statistically significant for $f / U_{u p}<2$, where it did not exceed 0.5. As the mean flow velocity increased, so did the magnitude of $\gamma_{w-w b}^{2}$. This trend reflects the changes in the turbulence structure as the bulk flow velocity grows. The frequency range at which $\gamma_{w-w b}^{2}$ attained highest values corresponds to the most energetic region in $S_{w b}$ (Fig. 8a) and lies between $f / U_{u p}=0.2$ and 0.7 (Fig. 7b). The highest magnitudes of $\gamma_{w-w b}^{2}$ for individual blades corresponded to smaller blades (not shown here).

The presence of a seaweed blade significantly modified the characteristics of the downstream flow region by reducing its total kinetic energy although enhancing its turbulence-related component. Compared to the conditions upstream of a blade, mean streamwise velocity decreased by $10-20 \%$, standard deviations of streamwise and vertical velocities were amplified by $40-100 \%$, and turbulent kinetic energy (TKE) increased by $50-200 \%$. It was verified that these effects were not due to the DMD influence and were associated with the blades. The strongest effects were recorded for the cases of 


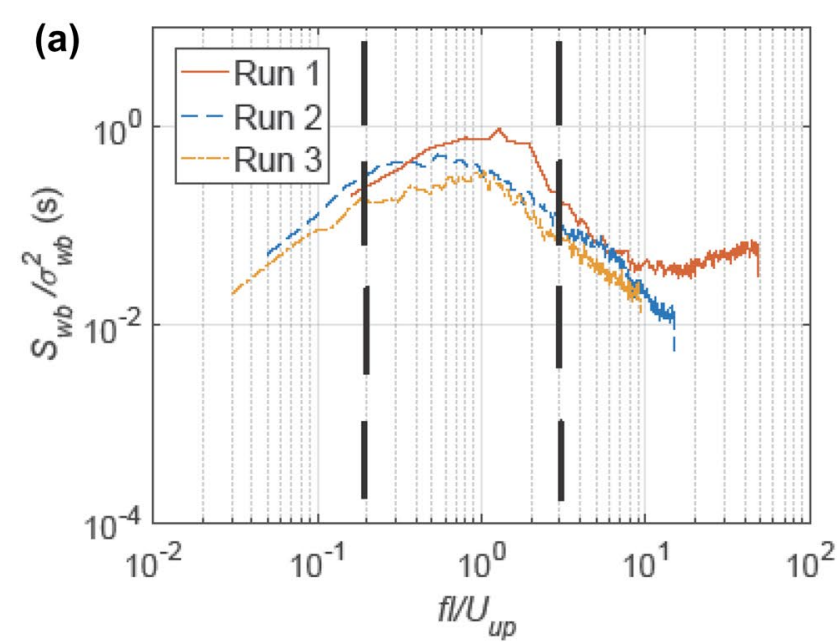

Fig. 8 Normalised spectra of the blade vertical velocity (a) and gain factors of the vertical flow velocity upstream of seaweed blade and the blade vertical velocity (b) as a function of the ratio of seaweed blade length $l$ to eddy wavelength $U_{u p} / f$. For each flow scenario (Run 1 , Run 2, Run 3), the curves represent averaged values across the data

large and ruffled blades. The effects of blades on the downstream wake turbulence were further investigated by using the gain factors (i.e. $|H(f)|^{2}=S_{u-d s} / S_{u-u p}$ and $|H(f)|^{2}=S_{w-d s} / S_{w-u p}$ ) of the streamwise (Fig. 9a) and vertical (Fig. 9b) flow velocities upstream and downstream of a seaweed blade. The scale ranges where turbulence enhancement occurred coincided for $u$ and $w$, being confined within $f / U_{u p}=3-40$.

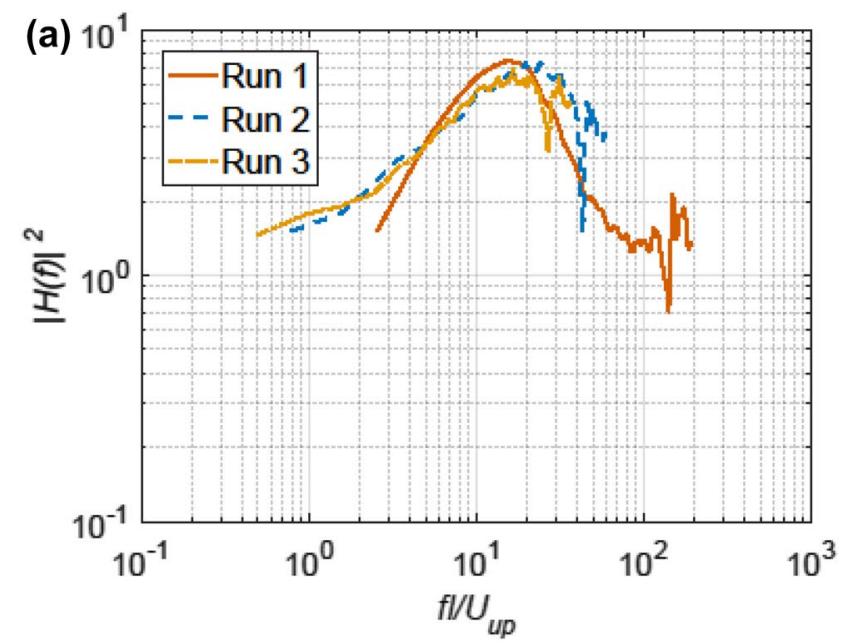

Fig. 9 Gain factors of the streamwise (a) and vertical (b) flow velocity components upstream and downstream of seaweed blades as a function of the ratio of seaweed blade length $l$ to the eddy wavelength

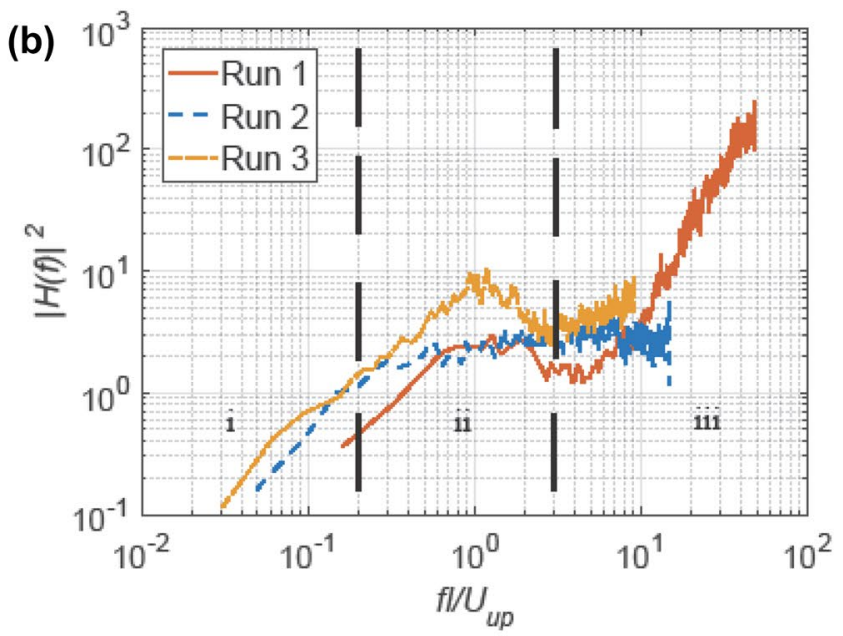

for five blades. Vertical dashed lines represent the limits of the spectral 'hill' region (a) and the limits of the regions describing different interactions between upstream vertical velocity and blade vertical velocity (b)

\section{Estimation of the thickness of the diffusion boundary layer at the blade surface}

The cross-correlation and spectral analyses showed that the blade frontal projected area was not significantly correlated with the approach velocity and drag force (Vettori 2016). Therefore, we can assume that the drag force acting on the blades was primarily due to viscous friction, while the pressure contribution was of secondary importance. This is physically reasonable for streamlined bodies such

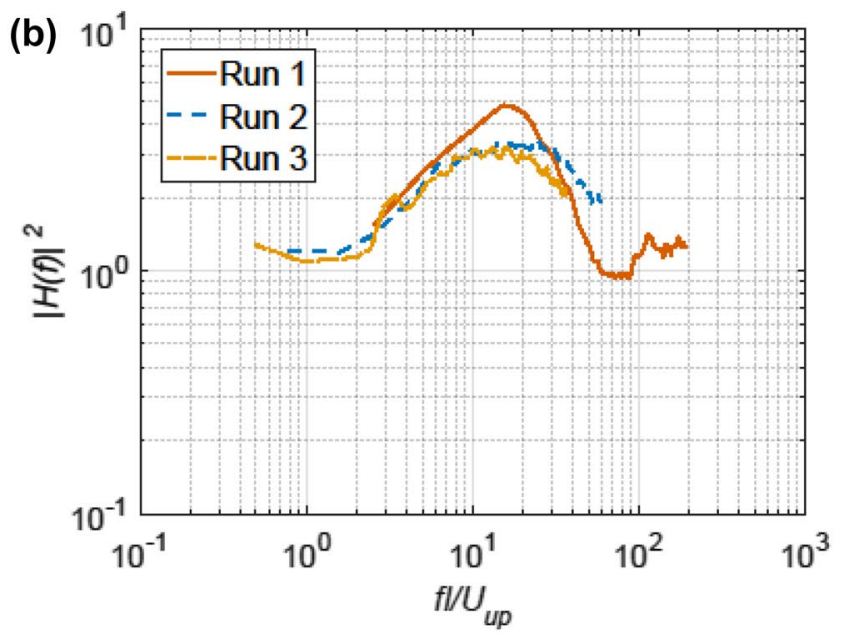

$U_{u p} / f$. For each flow scenario (Run 1, Run 2, Run 3), the curves represent averaged values across the data for five blades 
as seaweed blades. We can express the mean drag force $F_{d}$ on the blade as:

$F_{d}=\frac{1}{T} \int_{T} \int_{A_{\text {wet }}} \tau d A d t=\rho_{w} A_{w e t} u_{*}^{2}$

$u_{*}=\sqrt{\frac{F_{d}}{\rho_{w} A_{w e t}}}$

where $\tau$ is the instantaneous local viscous shear stress at the blade surface, $u_{*}$ is the blade-scale shear (or friction) velocity defined as $u_{*}=\left(\tau_{a v} / \rho_{w}\right)^{0.5}, T$ is averaging period, and $\tau_{a v}$ is the blade-averaged and time-averaged viscous stress. From the estimate of $u_{*}$, the thickness $\delta_{d}$ of the DBL was calculated according to the conventional diffusion theory and considering that molecular diffusivity $D_{m o l}$ of the most important solutes for photosynthesis in water is of the order of $10^{-9} \mathrm{~m}^{2} / \mathrm{s}$ (e.g. Boudreau and Jorgensen 2001), i.e.:

$\delta_{d}=\delta_{v} S_{c}^{-1 / 3}=10 \frac{v}{u_{*}}\left(\frac{v}{D_{m o l}}\right)^{-1 / 3} \approx \frac{v}{u_{*}}$

where $\delta_{v} \approx 10 v / u_{*}$ is the thickness of the viscous sublayer, and $S_{c}$ is the Schmidt number representing the ratio of the momentum diffusivity to the substance diffusivity. The application of Eq. (13) assumes that the flow around the blades is turbulent, with the presence of the viscous sublayer at the blade surface. This assumption is justified by two arguments: (1) the transition to turbulent boundary layer over seaweed blades is likely to occur at much smaller Reynolds numbers than conventionally perceived for flat plates (Re $\sim 10^{5}$; Hurd and Stevens 1997; Roberson and Coyer 2004); and, most importantly, (2) the flow regions in the vicinity of blade surfaces are already fully turbulent in our experiments (except for thin viscous sublayers at blade surfaces), as they are strongly influenced by the ambient flow which is fully turbulent. These two reasons would be also applicable for typical field conditions.

The data analysis shows that $u_{*}$ and $\delta_{d}$ were not influenced by the blade dimensions, depending mainly on the flow velocity, i.e. $u_{*}$ increased and $\delta_{d}$ decreased as the mean flow velocity increased (Table 3 ). The obtained estimates of $\delta_{d}$ are in agreement with values reported in Hurd and Pilditch
(2011) for the blades of $M$. pyrifera from a wave-sheltered site (i.e. $\delta_{d}=0.07-0.7 \mathrm{~mm}$ at $U_{u p}=0.008-0.045 \mathrm{~m} / \mathrm{s}$ ).

Note that the values in Table 3 relate to the mean shear velocity and mean (time-averaged) thickness of the DBL. Taking into consideration that the probability distribution of the drag force is near-Gaussian, the coefficient of variation $\sigma_{d} / F_{d}$ changes within a narrow range of 0.04-0.09, and following an approach similar to Eqs. (11) and (12), we can deduce that the thickness of the DBL varies in time within approximately $\pm 10 \%$ of its mean value.

\section{Discussion}

During the 80-min experiments the parameters $C_{d}, \sigma_{c d}, S k_{d}$, and $S_{d}$ decreased in time with most of the reduction occurring within the first 20-30 min (Fig. 4), after which time they became largely time-independent. These changes indicate that blades adjusted to the conditions in the flume facility relatively quickly. As reported by a number of authors (e.g. Boller and Carrington 2006), drag reduction occurs via blade reconfiguration, which seems to act via compaction of blade ruffled edges in the case of S. latissima. This mechanism cannot be measured using the video analysis technique applied in this study but can be visualised in the insets of Fig. 10. There are two factors that could have driven blade compaction in our case: a decrease in stiffness of seaweed material when exposed to freshwater that can facilitate reconfiguration, and/or action of the flow in which the blade is immersed. When exposed to salinity variation seaweeds regulate their turgor pressure to achieve a new steady state through osmotic adjustment (Kirst 1989; Hurd et al. 2014). In the present case, we expect that freshwater was absorbed by seaweeds leading to an increase in turgor pressure that was counteracted by release of metabolites such as mannitol (Reed and Wright 1986; Niklas 1992). This physiological response could have impacted on seaweed biomechanics and led to a reduction in stiffness. However, we suggest that blade acclimation to the flow hydraulics is the main factor to consider in the present case. In fact, results show that the drag reduction, estimated with the drag coefficient, depended on the hydraulic conditions, with a minimum reduction in 'Run 1' (in which case the mean flow velocity was similar to typical flow velocity observed at the collection site) and a maximum reduction in 'Run 3'. Blades achieved reduction
Table 3 Estimates of the normalised shear velocity and the thickness of the diffusive boundary layer at the surface of seaweed blades

\begin{tabular}{|c|c|c|c|c|c|c|c|c|c|c|}
\hline & \multicolumn{2}{|l|}{ G1 } & \multicolumn{2}{|l|}{ G2 } & \multicolumn{2}{|l|}{ G3 } & \multicolumn{2}{|l|}{ G4 } & \multicolumn{2}{|l|}{ G5 } \\
\hline & $\frac{u_{*}}{U_{u p}}$ & $\delta_{d}(\mathrm{~mm})$ & $\frac{u_{*}}{U_{u p}}$ & $\delta_{d}(\mathrm{~mm})$ & $\frac{u_{*}}{U_{u p}}$ & $\delta_{d}(\mathrm{~mm})$ & $\frac{u_{*}}{U_{u p}}$ & $\delta_{d}(\mathrm{~mm})$ & $\frac{u_{*}}{U_{u p}}$ & $\delta_{d}(\mathrm{~mm})$ \\
\hline Run 1 & 0.15 & 0.067 & 0.19 & 0.057 & 0.17 & 0.052 & 0.16 & 0.057 & 0.17 & 0.061 \\
\hline Run 2 & 0.13 & 0.023 & 0.14 & 0.022 & 0.15 & 0.020 & 0.13 & 0.023 & 0.15 & 0.019 \\
\hline Run 3 & 0.11 & 0.017 & 0.11 & 0.010 & 0.11 & 0.016 & 0.13 & 0.015 & 0.11 & 0.016 \\
\hline
\end{tabular}


Fig. 10 Dynamics of the mean drag force in time showing seaweed blade reconfiguration via video frames (insets). Data and images refer to blade G3 at flow scenario 'Run 3'. Note that images are not representative of the average position of the blade in the 10-min records; they are shown to illustrate the folding of blade ruffled edges

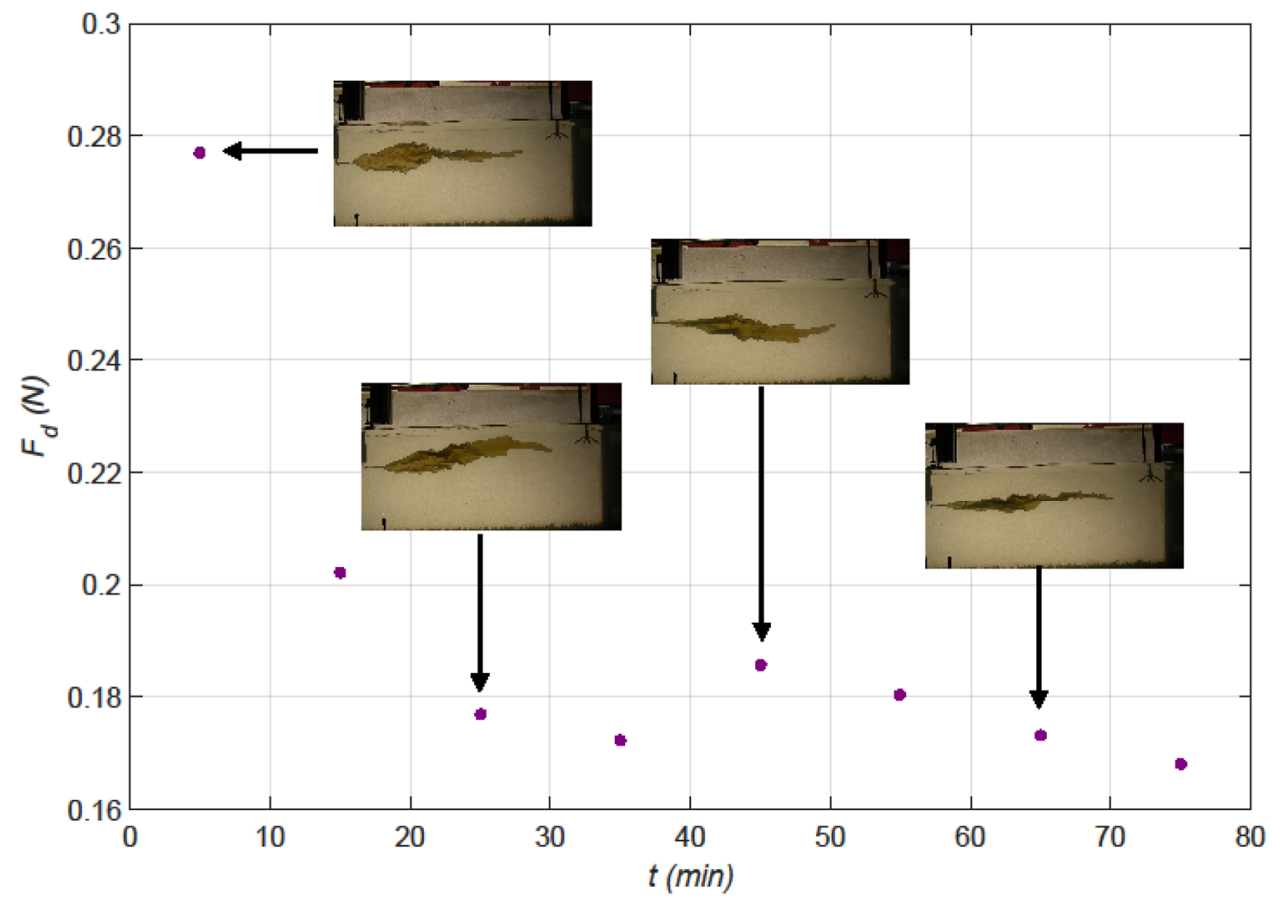

both in the mean drag and in the amplitude of drag fluctuations. The obtained results suggest that compaction can be a key mechanism in 'tensile plants' (sensu Nikora 2010), similar to considerations of Vogel (1989) for the case of tree leaves.

The effect of reconfiguration on the drag force can be 'quantified' using Vogel's exponent $\gamma$ in $F_{d} \propto U_{u p}^{2+\gamma}$ (Vogel 1994). For blades used in our experiments $\gamma$ ranged between -0.6 and -0.2 , consistent with the values reported by previous studies on seaweeds (e.g. Buck and Buchholz 2005). The mean drag coefficient decreased with the blade Reynolds number $R e_{l}$, but showed consistently higher values than those for flat plates (Fig. 5a) because of the effects of ruffles and bullations present on the surface of seaweed blades, approaching turbulence, and shape of the blades. Blade morphological macro-features affect the drag force experienced by blades considerably and need to be accounted for when blades are modelled (Vettori and Nikora 2019). That said, our estimates of the mean drag coefficient $C_{d}$ were considerably lower than the values reported in Buck and Buchholz (2005) for blades of $S$. latissima from a sheltered site at similar mean flow velocity. At $U_{u p} \approx 0.55 \mathrm{~m} / \mathrm{s}$ our results show $C_{d}=0.02-0.03$, while Buck and Buchholz (2005) reported values of $C_{d}$ between 0.04 and 0.1 . We suggest that the reason for this be twofold: (1) blades from Loch Fyne had a slender droplet shape (Vettori and Nikora 2017) that allowed a more efficient reconfiguration compared to the blades studied in Buck and Buchholz (2005); and (2) different response of the blades to a turbulent flow (i.e. the present study) compared to the case when the blades are towed in still water (i.e. Buck and Buchholz 2005).
Our results reveal that both incoming flow velocities and blade biomechanical characteristics contributed to the blade dynamics and their contributions depended on both hydraulic conditions and blade size. The flow action appeared to be predominant in highly energetic conditions (e.g. higher magnitudes of $\gamma_{u-d}^{2}$ and $\gamma_{w-w b}^{2}$, Fig. 7) and for smaller seaweed blades. We acquired the following new insights on how blade dynamics is affected by turbulent eddies of different sizes. Depending on the effects of the eddies on blade dynamics, we identified three regions in the domain of relative wavelength of $f l / U_{u p}$ :

1. At low frequencies, i.e. for the range of eddies with wavelength exceeding 5 times the blade length (i.e. $f l / U_{u p}<0.2$ ), blades dynamics is controlled by flow turbulence and passive flow-blade interactions occur. In other words, the blade motions passively follow motions of passing large eddies. This is reflected by high values of $\gamma_{u-d}^{2}, \gamma_{w-w b}^{2}\left(\right.$ Fig. 7) and $\left|\chi_{f}(f)\right|^{2}$ (Fig. 6b). Eddies of these sizes generate maximum drag fluctuations (Fig. 6a) but are not involved in active interactions with the blades (Fig. 8).

2. Blades dynamically interact with the eddies within a relatively broad intermediate range of wavelengths approximately between 0.3 and 5 times the blade length (i.e. $f l / U_{u p}=0.2-3$ ). Values of the coherence functions tended to decrease below the significance level in this range (Fig. 7), indicating that blade motion and drag were not primarily controlled by the incoming flow. The eddies within this wavelength range are the most 
efficient at driving blade dynamics as revealed by high values of $S_{w b} / \sigma_{w b}^{2}$ and $|H(f)|^{2}$ (Fig. 8).

3. The eddies with wavelength smaller than 0.3 times the blade length (i.e. $f / U_{u p}>3$ ) are too small to have considerable effects on blade dynamics. This is revealed by low values of $\gamma_{u-d}^{2}$ and $\gamma_{w-w b}^{2}$ (Fig. 7). The sharp increase of $|H(f)|^{2}$ in Fig. 8b at high frequencies in 'Run 1' does not reflect the effect of small eddies in powering blade motion, but it was rather caused by vortices shed by the blade free end. Seaweed blades enhanced wake eddies within this range of wavelengths, i.e. $f / U_{u p}=3-40$ (Fig. 9).

These findings suggest that depending on velocity spectra the seaweed blades may achieve an optimal length range where drag oscillations, which are the cause of seaweed breakage, are minimized. Blades with length between 0.2 and 3 times the wavelength of dominant eddies are expected to have a better physical and biological performance because they experience reduced drag oscillations and enhanced motion, which can boost nutrient uptake at low flow velocities.

Seaweed canopies/forests have a significant impact on the local hydrodynamics, attenuating currents (e.g. Jackson 1998; Gaylord et al. 2007; Rosman et al. 2007) and high frequency internal waves (e.g. Jackson 1984; Rosman et al. 2007). Also individual blades induce a considerable variation of the characteristics of the flow. The main effect is that of a reduction in the total kinetic energy (as its main contributor-mean velocity - reduces by up to 20\%) and a magnification of turbulence (TKE enhanced by up to $200 \%$ ), compared to the conditions upstream of a blade. Wake turbulence is generated predominantly at small scales (i.e. $f / U_{u p}=3-40$, Fig. 9), in agreement with findings from scaled models of kelp forest (Rosman et al. 2010). Vettori and Nikora (2018) report that at a distance from the blade free end equal to $4 l$ the variation in the mean streamwise velocity and TKE is down to $1 \%$ and $20 \%$, respectively, for physical models of seaweed blades. Because of their limited size, wake eddies generated by the blade free end do not actively interact with other (downstream) blades and are not expected to enhance nutrient uptake within a canopy/forest noticeably. On the other hand, in dense canopies, the cumulative effects of blades on the flow have consequences on the hydrodynamics at larger spatial scales. For example, within kelp forests turbulence level and mean velocity are very low and are likely to be the main limiting factor for kelp growth (e.g. Rosman et al. 2007).

Blade motion is a primary determinant of seaweed growth because it fosters light availability and enhances the potential nutrient uptake by reducing the thickness of the DBL $\delta_{d}$. For example, Hepburn et al. (2007) reported that oscillatory flow associated with wave-exposure enhanced the growth of
M. pyrifera at low levels of nitrogen by favouring seaweed motion. Huang et al. (2011) found that seaweed motion ameliorated fluxes through the DBL at low mean flow velocities. Measurements of $\delta_{d}$ on seaweed blades are relatively scarce and it remains unclear whether seaweed morphology and motion have a significant role in reducing $\delta_{d}$ and/or favouring the renewal of the DBL. Hurd and Pilditch (2011) investigated this issue by estimating $\delta_{d}$ via measurements of oxygen concentration from an $\mathrm{O}_{2}$ micro-optode. A major problem of techniques employed for direct measurements of $\delta_{d}$ is that they can be used only while samples are not moving. Therefore, measurements currently available refer to flow velocities lower than $0.1 \mathrm{~m} / \mathrm{s}$ and may not be representative of natural conditions. Indirect estimates of $\delta_{d}$ from measurements of the drag force used in the present study, on the other hand, are advantageous because they can be obtained regardless of blade motion and are averaged across the whole blade surface area, providing a practical metric at a blade scale. However, two important points are worth noting: (1) these estimates of $\delta_{d}$ are inherently biased-low as the underlying assumption is that drag is dominated by viscous friction at blade surfaces; and (2) this method is not applicable when pressure drag is significant (unless drag partitioning into pressure drag and viscous friction is possible). Our estimates of $\delta_{d}$ indicate that the DBL was thinned as the mean flow velocity increased, from $\delta_{d}=0.067 \mathrm{~mm}$ at $U_{u p}=0.1 \mathrm{~m} / \mathrm{s}$ to $\delta_{d}=0.010 \mathrm{~mm}$ at $U_{u p}=0.55 \mathrm{~m} / \mathrm{s}$. The values in 'Run 1' are within the range of $\delta_{d}$ reported by Hurd (2000) for similar mean flow velocities. It is also worth adding that the blade-averaged thickness of the DBL varies in time insignificantly, within $\pm 10 \%$ of its mean value.

\section{Conclusions}

In this study we explore flow-seaweed physical interactions at a blade scale in a unidirectional turbulent flow via laboratory experiments. Our results show that blades adjust to relatively fast flow conditions via reconfiguration mechanisms that allow blades to considerably reduce both the mean value and fluctuations of the drag force. The dynamics of seaweed blades is controlled by flow action and blade biomechanical characteristics (the first is dominant at high flow conditions). Depending on the size of turbulent eddies, blades interact with the flow differently. Eddies with wavelengths approximately between 0.3 and 5 times the blade length interact dynamically with blades. Even single blades have a substantial effect on the wake flow characteristics, reducing mean flow velocity and amplifying turbulence by shedding small eddies from their free end. We also estimated the thickness of the diffusive boundary layer at the blade surface from the measurements of the drag force and our values appear to be compatible with values reported from direct measurements. 
Acknowledgements The work described in this publication was undertaken during the Ph.D. study of Davide Vettori at the University of Aberdeen funded by a scholarship from the Northern Research Partnership, Scotland. The authors gratefully acknowledge: Peter Davies and Paul Mitchell for their support and guidance; David Attwood for his assistance during seaweed collection; Hamish Biggs for his assistance during seaweed collection and transport to the University of Aberdeen, and in setting up LED used to synchronise instruments; and Roy Gillanders and Benjamin Stratton for meticulous technical support. Many insightful comments provided by the Associate Editor Professor J. D. Ackerman and anonymous reviewer helped to improve the quality of the final manuscript.

Open Access This article is distributed under the terms of the Creative Commons Attribution 4.0 International License (http://creativeco mmons.org/licenses/by/4.0/), which permits unrestricted use, distribution, and reproduction in any medium, provided you give appropriate credit to the original author(s) and the source, provide a link to the Creative Commons license, and indicate if changes were made.

\section{References}

Batchelor GK (1967) An introduction to fluid dynamics. Cambridge University Press, Cambridge

Bendat JS, Piersol AG (2011) Random data: analysis and measurement procedures. Wiley, Hoboken

Boller ML, Carrington E (2006) The hydrodynamic effects of shape and size change during reconfiguration of a flexible macroalga. $\mathrm{J}$ Exp Biol 209(10):1894-1903

Boudreau BP, Jorgensen BB (2001) The benthic boundary layer: transport and biogeochemistry. Oxford University Press, Oxford

Buck BH, Buchholz CM (2005) Response of offshore cultivated Laminaria saccharina to hydrodynamic forcing in the North Sea. Aquaculture 250(3):674-691

Canny J (1986) A computational approach to edge detection. IEEE Trans Pattern Anal 6:679-698

Davidson P (2015) Turbulence: an introduction for scientists and engineers. Oxford University Press, Oxford

de Langre E (2008) Effects of wind on plants. Annu Rev Fluid Mech 40:141-168

Denny M (1994) Extreme drag forces and the survival of wind-and water-swept organisms. J Exp Biol 194(1):97-115

Dwivedi A, Melville B, Shamseldin AY (2010) Hydrodynamic forces generated on a spherical sediment particle during entrainment. $\mathrm{J}$ Hydraul Eng 136(10):756-769

Garcia CM, Jackson PR, Garcia MH (2006) Confidence intervals in the determination of turbulence parameters. Exp Fluids 40(4):514-522

Gaylord B, Rosman JH, Reed DC, Koseff JR, Fram J, MacIntyre S, Arkema K, McDonald C, Brzezinski MA, Largier JL, Monismith SG (2007) Spatial patterns of flow and their modification within and around a giant kelp forest. Limnol Oceanogr 52(5):1838-1852

Gerard VA (1987) Hydrodynamic streamlining of Laminaria saccharina Lamour. in response to mechanical stress. J Exp Mar Biol Ecol 107(3):237-244

Gerard VA, Mann KH (1979) Growth and production of Laminaria longicruris (Phaeophyta) populations exposed to different intensities of water movement. J Phycol 15(1):33-41

Goring DG, Nikora VI (2002) Despiking acoustic Doppler velocimeter data. J Hydraul Eng ASCE 128(1):117-126

Hepburn CD, Holborow JD, Wing SR, Frew RD, Hurd CL (2007) Exposure to waves enhances the growth rate and nitrogen status of the giant kelp Macrocystis pyrifera. Mar Ecol Prog Ser 339:99-108

Huang I, Rominger J, Nepf H (2011) The motion of kelp blades and the surface renewal model. Limnol Oceanogr 56(4):1453-1462

Hurd CL (2000) Water motion, marine macroalgal physiology, and production. J Phycol 36(3):453-472

Hurd CL, Pilditch CA (2011) Flow-induced morphological variations affect diffusion boundary-layer thickness of Macrocystis pyrifera (Heterokontophyta, Laminariales). J Phycol 47(2):341-351

Hurd CL, Stevens CL (1997) Flow visualization around single- and multiple-bladed seaweeds with various morphologies. J Phycol 33(3):360-367

Hurd CL, Harrison PJ, Druehl LD (1996) Effect of seawater velocity on inorganic nitrogen uptake by morphologically distinct forms of Macrocystis integrifolia from wave-sheltered and exposed sites. Mar Biol 126(2):205-214

Hurd CL, Harrison PJ, Bischof K, Lobban CS (2014) Seaweed ecology and physiology. Cambridge University Press, Cambridge

Jackson GA (1984) Internal wave attenuation by coastal kelp stands. J Phys Oceanogr 14(8):1300-1306

Jackson GA (1998) Currents in the high drag environment of a coastal kelp stand off California. Cont Shelf Res 17(15):1913-1928

Kirst GO (1989) Salinity tolerance of eukaryotic marine algae. Annu Rev Plant Physiol Plant Mol Biol 40:21-53

Koch EW (1994) Hydrodynamics, diffusion-boundary layers and photosynthesis of the seagrasses Thalassia testudinum and Cymodocea nodosa. Mar Biol 118(4):767-776

Koehl M, Alberte R (1988) Flow, flapping, and photosynthesis of Nereocystis luetkeana: a functional comparison of undulate and flat blade morphology. Mar Biol 99:435-444

Koehl MAR, Silk WK, Liang H, Mahadevan L (2008) How kelp produce blade shapes suited to different flow regimes: a new wrinkle. Integr Comp Biol 48:834-851

Monin AS, Yaglom AM (1971) Statistical fluid dynamics: mechanics of turbulence, vol 1. Dover Publications Inc., New York

Naudascher E, Rockwell D (2005) Flow-induced vibrations: an engineering guide. Dover Publications Inc., New York

Nepf HM (2012) Hydrodynamics of vegetated channels. J Hydraul Res 50(3):262-279

Niklas KJ (1992) Plant biomechanics: an engineering approach to plant form and function. University of Chicago Press, Chicago

Nikora V (2010) Hydrodynamics of aquatic ecosystems: an interface between ecology, biomechanics and environmental fluid mechanics. River Res Appl 26(4):367-384

Nortek (2004) Vectrino user guide. http://www.nortek-as.com/en/ support/manuals. Accessed 24 Jan 2018

Parsheh M, Sotiropoulos F, Porté-Agel F (2010) Estimation of power spectra of acoustic-Doppler velocimetry data contaminated with intermittent spikes. J Hydraul Eng ASCE 136(6):368-378

Reed RH, Wright PJ (1986) Release of mannitol from Pilayella littoralis (Phaeophyta: Ectocarpales) in response to hypoosmotic stress. Mar Ecol Prog Ser 29:205-208

Roberson LM, Coyer JA (2004) Variation in blade morphology of the kelp Eisenia arborea: incipient speciation due to local water motion? Mar Ecol Prog Ser 282:115-128

Rosman JH, Koseff JR, Monismith SG, Grover J (2007) A field investigation into the effects of a kelp forest (Macrocystis pyrifera) on coastal hydrodynamics and transport. J Geophys Res Oceans 112:C02016

Rosman JH, Monismith SG, Denny MW, Koseff JR (2010) Currents and turbulence within a kelp forest (Macrocystis pyrifera): insights from a dynamically scaled laboratory model. Limnol Oceanogr 55(3):1145-1158

Schlichting H, Gersten K (2000) Boundary-layer theory. Springer, Berlin 
Shumway RH, Stoffer DS (2000) Time series analysis and its applications. Springer, Berlin

Siniscalchi F, Nikora V (2012) Flow-plant interactions in openchannel flows: a comparative analysis of five freshwater plant species. Water Resour Res 48(5):2805-2814

Statzner B, Lamouroux N, Nikora V, Sagnes P (2006) The debate about drag and reconfiguration of freshwater macrophytes: comparing results obtained by three recently discussed approaches. Freshw Biol 51(11):2173-2183

Stevens CL, Hurd CL, Isachsen PE (2003) Modelling of diffusion boundary-layers in subtidal macroalgal canopies: the response to waves and currents. Aquat Sci 65(1):81-91

Vettori D (2016) Hydrodynamic performance of seaweed farms: an experimental study at seaweed blade scale. Doctoral dissertation, University of Aberdeen

Vettori D, Nikora V (2017) Morphological and mechanical properties of blades of Saccharina latissima. Estuar Coast Shelf Sci 196:1-9

Vettori D, Nikora V (2018) Flow-seaweed interactions: a laboratory study using blade models. Environ Fluid Mech 18:611-636
Vettori D, Nikora V (2019) Hydrodynamic performance of vegetation surrogates in hydraulic studies: a comparative analysis of seaweed blades and their physical models. J Hydraul Res. https:// doi.org/10.1080/00221686.2018.1562999

Vogel S (1989) Drag and reconfiguration of broad leaves in high winds. J Exp Bot 40(8):941-948

Vogel S (1994) Life in moving fluid. Princeton University Press, Princeton

Wheeler WN (1980) Effect of boundary layer transport on the fixation of carbon by the giant kelp Macrocystis pyrifera. Mar Biol 56(2): 103-110

Publisher's Note Springer Nature remains neutral with regard to jurisdictional claims in published maps and institutional affiliations. 